\title{
Clinical utility gene card for: Lynch syndrome (MLH1, MSH2, MSH6, PMS2, EPCAM) - update 2012
}

\author{
Nils Rahner ${ }^{\star}, 1$, Verena Steinke ${ }^{2}$, Brigitte Schlegelberger ${ }^{3}$, Francois Eisinger ${ }^{4}$, Pierre Hutter ${ }^{5}$ \\ and Sylviane Olschwang ${ }^{4}$
}

European Journal of Human Genetics (2013) 21, doi:10.1038/ejhg.2012.164; published online 15 August 2012

Update to: European Journal of Human Genetics (2010) 18, 1069; doi:10.1038/ejhg.2009.232; published online 27 January 2010

\section{DISEASE CHARACTERISTICS \\ 1.1 Name of the disease (synonyms) \\ Lynch syndrome/HNPCC.}

1.2 OMIM\# of the disease

276300,613244

1.3 Name of the analysed genes or DNA/chromosome segments MLH1, MSH2, MSH6, PMS2, and EPCAM.

1.4 OMIM\# of the gene(s)

MLH1 (120436), MSH2 (609309), MSH6 (600678), PMS2 (600259), EPCAM (185535).

\subsection{Mutational spectrum}

Point mutations, large deletions and duplications, large genomic insertions and promoter methylation.

\subsection{Analytical methods}

Stepwise analyses:

1. Clinical selection according to the Amsterdam II criteria and revised Bethesda guidelines. ${ }^{1,2}$

2. Study of MMR function in tumour cells ${ }^{3,4}$ : Immunohistochemical (IHC) study of the four mismatch repair proteins MLH1, MSH2, MSH6, and PMS2. In case of absence of the MLH1 protein, BRAF codon 600 characterisation by pyrosequencing, sequencing, TaqMan, SNaPshot, and so on and somatic methylation analysis of the MLH1 promotor could help to distinguish sporadic from Lynch-associated cancers. In case of an ambiguous result in immunohistochemistry, microsatellite DNA analysis - genotyping of the consensus panel of five mononucleotidic repeats defined in 1998 should be performed additionally ${ }^{5}$ (pathogenic missense mutation might be missed without microsatellite analysis ${ }^{6}$ ). May vary with national settings.

3. Germline analysis ${ }^{7,8}$ : The pattern of staining in IHC is suggestive for the underlying gene defect (loss of MLH1/PMS2 - analysis of
MLH1; loss of MSH2/MSH6 - analysis of MSH2; isolated loss of MSH6 - analysis of MSH6; isolated loss of PMS2 - analysis of PMS2). Germline analysis should include search for point mutations and large genomic deletions/duplications/insertions (e.g., by pre-screening (DHPLC), direct sequencing on gDNA or cDNA level, MLPA including promoter regions and EPCAM gene, Southern blot analysis). Mutation analysis of PMS2 should include the analysis on RNA. $^{9}$ Germline $M L H 1$ promoter methylation characterisation by MSP, bisulphite pyrosequencing, or MLPA (useful for diagnostic purpose, not for predictive testing).

\subsection{Analytical validation}

Confirmation of mutation in an independent biological sample of the index case or an affected relative.

In case of deletion/duplication of one exon, confirm with a second technique/kit based on different primers.

\subsection{Estimated frequency of the disease}

(Incidence at birth ('birth prevalence') or population prevalence) Prevalence in colorectal cancer patients about $1-3 \% .{ }^{10}$

Estimated prevalence in population about 1:660-1:2000. ${ }^{11}$

1.9 If applicable, prevalence in the ethnic group of investigated person

Not applicable.

\subsection{Diagnostic setting}

\begin{tabular}{llc} 
& Yes & No \\
A. (Differential) diagnostics & $\bigotimes$ & $\square$ \\
B. Predictive testing & $\bigotimes$ & $\square$ \\
C. Risk assessment in relatives & $\bigotimes$ & $\square$ \\
D. Prenatal & $\bigotimes$ & $\square$ \\
\hline
\end{tabular}

Comment: Prenatal diagnostic may vary with national settings.

\footnotetext{
${ }^{1}$ Medical Faculty, Institute of Human Genetics, University of Dusseldorf, Dusseldorf, Germany; ${ }^{2}$ Institute of Human Genetics, University of Bonn, Bonn, Germany; ${ }^{3}$ Hannover Medical School, Institute for Cellular and Molecular Pathology, Hannover, Germany; ${ }^{4}$ Centre de Recherches en Cancerologie de Marseille, Institut Paoli Calmettes, Marseille, France; 5 Unit of Genetics, Institut Central des Hopitaux Valaisans, Sion, Switzerland

${ }^{*}$ Correspondence: Dr N Rahner, Institute of Human Genetics, University of Dusseldorf, Universitaetsstrasse 1, 40225 Dusseldorf, Germany. Tel: +49211 8112355 ;

Fax: +49 21181 12538; E-mail: nils.rahner@uni-duesseldorf.de
} 


\section{TEST CHARACTERISTICS}

\begin{tabular}{|c|c|c|c|c|}
\hline & \multicolumn{2}{|c|}{ Genotype or disease } & \multirow{2}{*}{$\begin{array}{l}\text { A: True positives } \\
\text { B: False positives }\end{array}$} & \multirow{2}{*}{$\begin{array}{l}\text { C: False negative } \\
\text { D: True negative }\end{array}$} \\
\hline & Present & Absent & & \\
\hline \multicolumn{5}{|l|}{ Test } \\
\hline \multirow[t]{2}{*}{ Positive } & $A$ & B & Sensitivity: & $A /(A+C)$ \\
\hline & & & Specificity: & $D /(D+B)$ \\
\hline \multirow[t]{2}{*}{ Negative } & C & D & Positive predictive value: & $A /(A+B)$ \\
\hline & & & Negative predictive value: & $D /(C+D)$ \\
\hline
\end{tabular}

\subsection{Analytical sensitivity}

(proportion of positive tests if the genotype is present)

Almost 100\%.

(in case of mutation analysis in the coding area, common splice sites, large genomic deletions/duplications).

\subsection{Analytical specificity}

(proportion of negative tests if the genotype is not present)

Almost 100\%.

Assuming a complete screening of all genes.

Variants of unknown significance might be re-classified as deleterious a posteriori.

\subsection{Clinical sensitivity}

(proportion of positive tests if the disease is present)

The clinical sensitivity can be dependent on variable factors such as age or family history. In such cases, a general statement should be given, even if a quantification can only be made case by case.

Not high. Dependent on the indication criteria and the molecular strategy used (primary screening with MSI and IHC or not). Computed by predictive models. ${ }^{12}$

\subsection{Clinical specificity}

(proportion of negative tests if the disease is not present)

The clinical specificity can be dependent on variable factors such as age or family history. In such cases, a general statement should be given, even if a quantification can only be made case by case.

Unknown.

The test has no clinical specificity that goes beyond the analytical specificity (see 2.2) since it is not a test for cancer but for cancer risk.

\subsection{Positive clinical predictive value}

(life-time risk to develop the disease if the test is positive)

Up to $\sim 80 \%$. Dependent, for example, on the affected $M M R$ gene and gender. ${ }^{13}$

\subsection{Negative clinical predictive value}

(probability not to develop the disease if the test is negative)

Assume an increased risk based on family history for a non-affected person. Allelic and locus heterogeneity may need to be considered.

Index case in that family had been tested:

The index case in a family has usually already developed cancer before the genetic test.

Index case in that family had not been tested:

This is an unusual and not recommended approach.

\section{CLINICAL UTILITY}

3.1 (Differential) diagnosis: The tested person is clinically affected (To be answered if in 1.10 'A' was marked)

\subsubsection{Can a diagnosis be made other than through a genetic test?}

$\begin{array}{ll}\text { No } & \square \text { (continue with 3.1.4) } \\ \text { Yes } & \text { Clinically } \\ & \text { Imaging } \\ & \text { Endoscopy } \\ & \text { Biochemistry } \\ & \text { Electrophysiology } \\ & \text { Other (please describe) }\end{array}$

3.1.2 Describe the burden of alternative diagnostic methods to the patient

Not applicable.

3.1.3 How is the cost effectiveness of alternative diagnostic methods to be judged?

Not applicable.

3.1.4 Will disease management be influenced by the result of a genetic test?

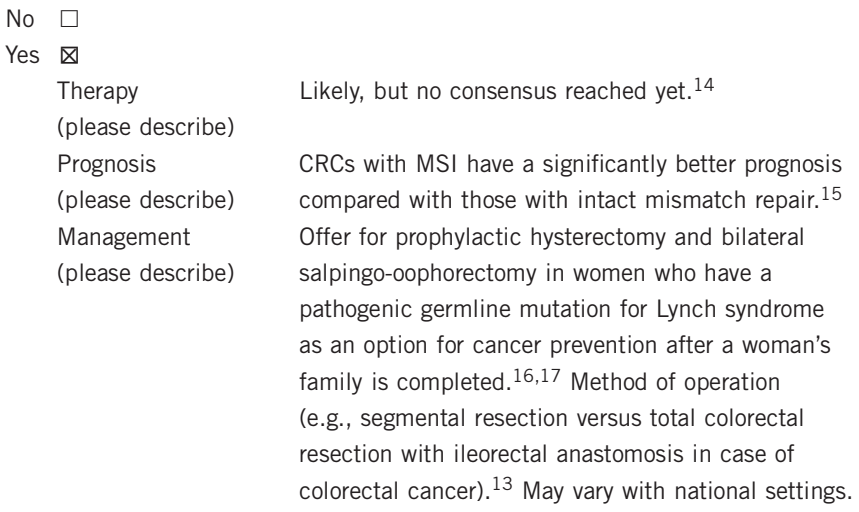

CRCs with MSI have a significantly better prognosis compared with those with intact mismatch repair. ${ }^{15}$ Offer for prophylactic hysterectomy and bilateral salpingo-oophorectomy in women who have a pathogenic germline mutation for Lynch syndrome as an option for cancer prevention after a woman's family is completed. ${ }^{16,17}$ Method of operation (e.g., segmental resection versus total colorectal resection with ileorectal anastomosis in case of colorectal cancer). ${ }^{13}$ May vary with national settings.

3.2 Predictive setting: The tested person is clinically unaffected but carries an increased risk based on family history

(To be answered if in 1.10 'B' was marked)

3.2.1 Will the result of a genetic test influence lifestyle and prevention?

If the test result is positive (please describe):

Yes. ${ }^{18,19}$ Yearly/two-yearly colorectal cancer screening with complete colonoscopy (and chromocolonoscopy with indigo-carmine) from age 20 to 25. May vary with national settings.

Yearly gynaecological examination; transvaginal sonography in women starting at age 30 . May vary with national settings.

If the test result is negative (please describe):

Intensified screening not required. Screening as recommended for the general population (according to the country guidelines).

3.2.2 Which options in view of lifestyle and prevention does a person at-risk have if no genetic test has been done (please describe)?

Yearly/two-yearly colorectal cancer screening with complete colonoscopy (and chromocolonoscopy with indigo-carmine) from age 20 to 25. May vary with national settings.

Yearly gynaecological examination; transvaginal sonography in women starting at age 30 . May vary with national settings.

Cancer prevention with Aspirin under investigation. ${ }^{14}$ 
3.3 Genetic risk assessment in family members of a diseased person (To be answered if in 1.10 ' $\mathrm{C}$ ' was marked)

\subsubsection{Does the result of a genetic test resolve the genetic situation in that family?}

Yes, autosomal dominant inheritance.

3.3.2 Can a genetic test in the index patient save genetic or other tests in family members?

Yes, recommendation for screening applies only to mutation carriers and persons at risk.

\subsubsection{Does a positive genetic test result in the index patient enable a predictive test in a family member?}

Yes.

\subsection{Prenatal diagnosis}

(To be answered if in 1.10 'D' was marked)

\subsubsection{Does a positive genetic test result in the index patient enable a} prenatal diagnosis?

Technically feasible, generally not recommended, may vary with national settings.

\section{IF APPLICABLE, FURTHER CONSEQUENCES OF TESTING}

Please assume that the result of a genetic test has no immediate medical consequences. Is there any evidence that a genetic test is nevertheless useful for the patient or his/her relatives? (Please describe)

Support for family life organisation.

Cause assessment of a severe disease, known to be transmissible to next generations.

Efficiency of subsequent clinical management.

Risk calculation of unaffected relatives.

\section{CONFLICT OF INTEREST}

The authors declare no conflict of interest.

\section{ACKNOWLEDGEMENTS}

This work was supported by EuroGentest2 (Unit 2: 'Genetic testing as part of health care'), a Coordination Action under FP7 (Grant agreement number 261469), and the European Society of Human Genetics.
1 Vasen HF, Watson P, Mecklin JP, Lynch HT: New clinical criteria for hereditary nonpolyposis colorectal cancer (HNPCC, Lynch syndrome) proposed by the International Collaborative group on HNPCC. Gastroenterology 1999; 116: 1453-1456.

2 Umar A, Boland CR, Terdiman JP et al: Revised Bethesda Guidelines for hereditary nonpolyposis colorectal cancer (Lynch syndrome) and microsatellite instability. J Natl Cancer Inst 2004; 96: 261-268.

3 Loughrey MB, Waring PM, Tan A et al: Incorporation of somatic BRAF mutation testing into an algorithm for the investigation of hereditary non-polyposis colorectal cancer. Fam Cancer 2007; 6: 301-310.

4 Shia J: Immunohistochemistry versus microsatellite instability testing for screening colorectal cancer patients at risk for hereditary nonpolyposis colorectal cancer syndrome. Part I. The utility of immunohistochemistry. J Mol Diagn 2008; 10: 293-300.

5 Boland CR, Thibodeau SN, Hamilton SR et al: A National Cancer Institute Workshop on Microsatellite Instability for cancer detection and familial predisposition: development of international criteria for the determination of microsatellite instability in colorectal cancer. Cancer Res 1998; 58: 5248-5257.

6 Halvarsson B, Lindblom A, Rambech E, Lagerstedt K, Nilbert M: Microsatellite instability analysis and/or immunostaining for the diagnosis of hereditary nonpolyposis colorectal cancer? Virchows Arch 2004; 444: 135-141.

7 Grover S, Syngal S: Genetic testing in gastroenterology: Lynch syndrome. Best Pract Res Clin Gastroenterol 2009; 23: 185-196.

8 Niessen RC, Hofstra RM, Westers $\mathrm{H}$ et al: Germline hypermethylation of MLH1 and EPCAM deletions are a frequent cause of Lynch syndrome. Genes Chromosomes Cancer 2009; 48: 737-744.

9 Etzler J, Peyrl A, Zatkova A et al: RNA-based mutation analysis identifies an unusual MSH6 splicing defect and circumvents PMS2 pseudogene interference. Hum Mutat 2008; 29: 299-305.

10 Lamberti C, Mangold E, Pagenstecher C et al: Frequency of hereditary non-polyposis colorectal cancer among unselected patients with colorectal cancer in Germany. Digestion 2006; 74: 58-67.

11 de la Chapelle A: The incidence of Lynch syndrome. Fam Cancer 2005; 4: 233-237.

12 Tresallet $C$, Brouquet $A$, Julié $C$ et al: Evaluation of predictive models in daily practice for the identification of patients with Lynch syndrome. Int J Cancer 2012; 130: 1367-1377.

13 Vasen HF, Möslein G, Alonso A et al: Guidelines for the clinical management of Lynch syndrome (hereditary non-polyposis cancer). J Med Genet 2007; 44: 353-362.

14 Burn J, Gerdes AM, Macrae F et al: Long-term effect of aspirin on cancer risk in carriers of hereditary colorectal cancer: an analysis from the CAPP2 randomised controlled trial. Lancet 2011; 378: 2081-2087.

15 Popat S, Hubner R, Houlston RS: Systematic review of microsatellite instability and colorectal cancer prognosis. J Clin Oncol 2005; 23: 609-618.

16 Schmeler KM, Lynch HT, Chen LM et al: Prophylactic surgery to reduce the risk of gynecologic cancers in the Lynch syndrome. N Engl J Med 2006; 354: 261-269.

17 Celentano V, Luglio G, Antonelli G et al: Prophylactic surgery in Lynch syndrome. Tech Coloproctol 2011; 15: 129-134.

18 Stoffel E, Mukherjee B, Raymond VM et al: Calculation of risk of colorectal and endometrial cancer among patients with Lynch syndrome. Gastroenterology 2009; 137: 1621-1627.

19 Krausz C, Quintana-Murci L, McElreavey K: Prognostic value of deletion analysis: what is the clinical prognostic value of $Y$ chromosome microdeletion analysis? Hum Reprod 2000; 15: 1431-1434. 